Artig O

$\infty$

\title{
Abordagem da PANDEMia POR COVID-I 9 NA CIDADE DE IPAUSSU COM I 4 MIL HABITANTES NO interior do Estado de São Paulo
}

\section{Autores:}

Renata Aparecida Pimentel Rissoni ${ }^{1}$

Renato Demarchi Foresto ${ }^{2}$

Francisco Rafael de Oliveira ${ }^{2}$

Ruan de Andrade Fernandes ${ }^{2}$

Mônica Rika Nakamura ${ }^{2}$

Marina Pontello Cristelli ${ }^{2}$

José Medina Pestana ${ }^{2}$

E-mail: rdforesto@gmail.com

Hospital do Rim. Rua Borges Lagoa, $960-11^{\circ}$

andar. Vila Clementino - São Paulo/SP.

CEP 04038-002.

\section{Instituiçóes}

1. Secretaria de Saúde - Prefeitura de Ipaussu

/ Sáo Paulo

2. Hospital do Rim. Disciplina de Nefrologia Universidade Federal de São Paulo

\section{INTRODUÇÃO}

A doença por Coronavírus 2019 (COVID-19) espalhou-se amplamente em todo o mundo, com mais de 60 milhóes de casos confirmados e 1,5 milhão de mortes até 27 de novembro de 2020 [1]. No Brasil, a disseminação da doença se iniciou em 26 de fevereiro, com o primeiro caso registrado na cidade de São Paulo. Desde então, o Brasil enfrenta desafios maiores agravados pela sua vasta extensão territorial, cidades com alta densidade populacional com grande fluxo de pessoas, regióes com acentuada disparidade em relação ao acesso à testagem e aos cuidados intensivos adequados e, principalmente, falta de uniformidade nas políticas públicas implementadas para o combate à doença entre os diversos níveis administrativos.

Diante de uma pandemia sem precedentes, os modelos de política pública para enfrentamento descritos são escassos. É de fundamental importância a compreensão da disseminação do vírus enquanto não houver medicamentos ou vacinas seguras e eficazes disponíveis. Neste momento, medidas para prevenção de contágio são as estratégias mais eficazes para o combate à pandemia COVID-19 [2].

No Estado de São Paulo, foi criado um comitê de contingência à COVID-19 em 13 de março e, através do Decreto No 64.994, de 28 de maio de 2020, foi instituído o "Plano São Paulo" para combate à pandemia [3]. Nesse Plano, cada microrregião, ou Departamento Regional de Saúde (DRS), tem 
seus indicativos de saúde intensamente monitorados a fim de fornecimento de recursos materiais e execução de estratégias mais adequadas de acordo com a gravidade da disseminação do vírus.

$\mathrm{Na}$ região Sudoeste do Estado de São Paulo, o pequeno município de Ipaussu implementou medidas preventivas e açóes comunitárias que impactaram positivamente os desfechos da doença na cidade. Aqui, descreveremos o modelo de enfrentamento à pandemia adotado por uma cidade do interior do Estado de São Paulo, que seguiu todas as recomendaçóes de políticas públicas na implementação de açôes comunitárias que mitigaram os efeitos locais de disseminação da doença.

\section{ASPECTOS DEMOGRÁFICOS DE IPAUSSU/SP}

O município de Ipaussu integra o Departamento Regional de Saúde de Marília (17 ao todo no Estado), compondo a regiáo de saúde de Ourinhos (63 em todo o Estado), na região Sudoeste do Estado de Sáo Paulo. Possui área territorial de aproximadamente 209,6 km2 e população estimada em 14.506 habitantes, com 50,2\% do sexo masculino com $87 \%$ de sua população vivendo na zona urbana. A taxa de alfabetização é de $90 \%$ e a expectativa de vida geral da populaçáo de 74,9 anos. O município possui IDH
(Índice de Desenvolvimento Humano) de 0,795 , considerado alto, maior que a média nacional de 0,761 , situando-se em $1.107^{\circ}$ lugar no Brasil, porém inferior ao IDH do Estado de São Paulo, de 0,826.

A economia do município está basicamente voltada para a agricultura, predominando cultivo de cana de açúcar. O PIB (Produto Interno Bruto) per capita de Ipaussu é de 25 mil reais, menor que o PIB per capita brasileiro (32 mil reais) e o paulista (52 mil reais), colocando-se em $1.654^{\circ}$ lugar na lista de 5.570 municípios brasileiros, segundo a divulgação pelo IBGE em 2019.

\section{ESTRUTURA E FUNCIONAMENTO DO SERVIÇO MUNICIPAL DE SAÚDE}

Do orçamento anual de $\mathrm{R} \$ 54,7$ milhóes da cidade, $28,9 \% \quad(\mathrm{R} \$ \quad 15,8$ milhôes) é destinado à Saúde. O município conta com 01 Unidade Básica de Saúde, 02 Unidades do Programa de Saúde da Família, 02 Clínicas de Fisioterapia, 01 Fisioterapia Domiciliar, 01 unidade básica do Serviço de Atendimento Móvel de Urgência (SAMU) e um Hospital Geral (“Santa Casa de Ipaussu”), sob cogestáo municipal, com 48 leitos de enfermaria, sem leitos em unidade de terapia intensiva. Os casos com maior complexidade clínica ou aqueles que necessitam de suporte de terapia intensiva sáo encaminhados para a cidade de Ourinhos, a $30 \mathrm{~km}$ de distância, 
ou para Santa Cruz do Rio Pardo, localizado a $19 \mathrm{~km}$ de Ipaussu.

\section{Medidas DE ENFRENTAMENTO}

\section{À PANDEMIA}

Logo após a OMS decretar a COVID19 como pandemia, a cidade decretou medidas de prevenção em 17 de março, que estão descritas a seguir, em ordem cronológica, tendo como referência o dia da confirmação do primeiro caso em Ipaussu (denominado D0): a) Vacinação $\mathrm{da}$ populaçáo contra Influenza (D-66) - devido ao risco de escassez de leitos, iniciou-se a campanha de prevençáo às outras doenças com potencial de internação, como a Gripe. A campanha de vacinação contra Influenza, que já ocorre anualmente, foi intensificada pelo alerta da pandemia e necessidade de prevenção de outros vírus respiratórios. A ação foi realizada em área externa, minimizando o risco de contágio; b) Início da entrega de máscaras faciais (D65) - foram distribuídas 45.000 máscaras faciais para a população em diversos pontos da cidade, com orientação dos protocolos sanitários para seu uso; c) Instituições de barreiras sanitárias (D-61) — instituídas barreiras de parada obrigatória de pessoas e veículos nos 5 pontos de entrada ou saída da cidade com aferição de temperatura, arguição de sintomas e orientaçôes de prevenção. As barreiras permaneceram por 6 meses, até 20 de Setembro, com previsáo de retomada se necessário; d) Visita de orientação às empresas e comércios (D-51) — uma equipe da vigilância sanitária da secretaria de saúde foi designada para realizar açôes de prevenção no comércio local e nas empresas, com entrega de máscaras e orientaçôes de higiene e distanciamento social; e) Habilitada uma ala de enfermaria na Santa Casa destinada aos pacientes com COVID-19 (D-40), com reforma e implementação de uma ala hospitalar com 10 leitos para isolamento dos pacientes com COVID-19 com critérios de internaçáo hospitalar, sem necessidade de cuidados intensivos; f) Adoção de um sistema de monitoramento da pandemia (D-30) - além dos sistemas e-SUS VE e SIVEP-Gripe para notificação, foi adotado um sistema privado para monitoramento local dos casos e divulgação nas mídias sociais para a população; g) Testagem dos pacientes com RT-PCR com resultado em até 24 horas $(\mathrm{D}+25)$, considerando que o diagnóstico é a pedra angular para o controle da disseminação do vírus, para detecção e isolamento dos casos. Entre os primeiros testes RT-PCR realizados, o resultado era disponibilizado, em média, 7 dias após a coleta, e a parceria com o Hospital do Rim em São Paulo, reduziu a obtenção deste resultado para 24 a 48 horas; h) Visita domiciliar $(\mathrm{D}+45)$ — os agentes de saúde iniciaram visitas domiciliares para orientação 
de cuidados e entrega de kits com produtos usuais de higiene. Os domicílios foram selecionados de acordo com o mapeamento dos casos na cidade, dando prioridade para os bairros mais acometidos e casas próximas ao comércio, alcançando $80 \%$ dos domicílios; i) Instalaçáo do Centro de Atendimento à COVID-19 (D+46), com estrutura para centralizar o atendimento e testagem dos pacientes suspeitos, evitando aglomeração nas unidades de PSF e UBS, prevenindo o aumento do risco de transmissão para outros pacientes; j) Estaçôes "drive thru" para vacinaçáo $(\mathrm{D}+90)$ - retomada da campanha de vacinação contra Influenza, incluindo a tríplice viral, como oportunidade de ampliação de cobertura vacinal e prevenção de doenças concomitantes; k) Inquérito sorológico dos pacientes com COVID-19 e seus contatos domiciliares (D+92) em 1.498 pessoas (cerca de $10,1 \%$ da população local) para compreensão tanto da imunogenicidade quanto da transmissibilidade em contatos assintomáticos.

\section{Parceria com hospitais de REFERÊNCIA E CENTROS DE PESQUISA}

O Hospital do Rim forneceu testes RTPCR para SARS-CoV-2 para realização nos casos suspeitos, com entrega do resultado dentro de 24 horas da coleta, otimizando os cuidados e permitindo o isolamento pre- coce dos casos confirmados, reduzindo a disseminação. Além da parceria construída com o Hospital do Rim, foram elaborados projetos de pesquisa para realização de inquérito sorológico na população local, investigação da resposta sorológica, modelos de disseminaçáo e comportamento viral e a influência da variabilidade genética $\mathrm{da}$ populaçáo na evolução da doença, com o Laboratório de Pesquisa da Disciplina de Nefrologia da Universidade Federal de São Paulo e com o Laboratório de Genética e Cardiologia Molecular do Instituto do Coração (São Paulo).

\section{RESUltados}

O primeiro caso em Ipaussu foi diagnosticado em 29 de maio, 22a semana epidemiológica. $\mathrm{O}$ paciente era um morador externo que visitou a cidade. A partir dessa data, novos casos foram diagnosticados em residentes de Ipaussu que trabalham nas cidades vizinhas, a partir dos quais, a disseminação interna se iniciou, contando com 354 casos e 4 óbitos até 27 de novembro (Figura 1). Em comparação com o Estado de Sáo Paulo, Ipaussu teve incidência de 1 caso para 41 habitantes, contra 1 caso para 35. A mortalidade foi de 1 caso em 3.626 habitantes, contra 1 em 846 no Estado de Sáo Paulo. A letalidade foi de 1,3\% em Ipaussu e 3,4\% em São Paulo. 
Houve o pico de incidência dos casos já na $6^{a}$ semana após o diagnóstico do primeiro caso na cidade, $28^{\mathrm{a}}$ semana epidemiológica, sendo diagnosticadas 41 pessoas com COVID-19 (Figura 2). Sobre a distribuição geográfica dos casos, após o surto inicial localizado em um dos bairros, houve uma disseminaçáo para toda a cidade, com distribuição atual disseminada (Figura 3).

Dentre as faixas etárias, predominou entre 20 a 39 anos, onde $3,1 \%$ adquiriu COVID-19, seguido de 2,9\% da populaçáo entre 40-59 anos. As populaçóes entre $0 \mathrm{a}$ 9 anos e 10 a 19 anos tiveram as menores incidências de casos, $1,1 \%$ e $1,4 \%$, respectivamente. Na população idosa, a incidência foi menor que na população adulta $(2,3 \%)$, porém nessa faixa etária ocorreram os 4 óbitos, com letalidade de 1,3\% (Tabela 1). A população de Ipaussu tem uma distribuição igualitária em relaçáo ao gênero, com as mulheres correspondendo a 49,8\% da população total. Porém, no geral, o número de casos prevaleceu entre as mulheres $(53,4 \%$ dos casos), com predomínio masculino em algumas faixas etárias.

Através da parceria com o Hospital do Rim, foi realizado o inquérito sorológico com recrutamento de 1.498 pessoas, aproximadamente $10,1 \%$ da populaçáo local. A coleta dos exames foi realizada entre agosto e setembro/2020. Até o início do estudo, 289 pessoas foram diagnosticadas com COVID-19, todas incluídas no inquérito.
Além dessas pessoas, foram incluídos os contatos domiciliares desses pacientes, profissionais de saúde, gestantes e grupos de risco (hipertensos, diabéticos e obesos). No geral, a soroprevalência na populaçáo foi de $12,2 \%$. Nos pacientes com diagnóstico prévio de COVID-19, a soroprevalência foi de $84,5 \%$, seguido dos contatos domiciliares, com 14,4\%; em profissionais de saúde, a soroprevalência foi de 1,3\%. A investigação sobre o modo de transmissáo da doença demonstrou que $67 \%$ dos casos teve aquisiçáo comunitária e $33 \%$ foi desconhecida, sendo que nenhum caso teve transmissão intrahospitalar na cidade (Tabela 1).

\section{Discussão}

No modelo de combate à pandemia implementado em Ipaussu, foi possível seguir todas as recomendaçóes de política pública em escala municipal. $\mathrm{O}$ tamanho pequeno da população e a baixa atividade econômica local contribuíram com o controle da doença, entretanto, a cidade atuou nas principais frentes, como a realizaçáo de campanhas maciças e ininterruptas de prevençáo com distribuição de máscaras, orientação de higiene e distanciamento social, fornecimento de ampla cobertura de testes diagnósticos e sorológicos, testagem precoce com resultado rápido para isolamento dos casos confirmados e busca ativa de financiamento e 
parcerias com centros de referência para consultoria e desenvolvimento de pesquisa.

$\mathrm{O}$ inquérito sorológico obteve uma amostra significativa da população da cidade $(10,1 \%)$, demonstrando que uma parcela ainda pequena da população teve contato com o vírus $(12,2 \%)$ e que a maioria das pessoas ainda permanece suscetível à doença, o que corrobora a necessidade de se manter os cuidados de prevenção.

Dentre as dificuldades encontradas durante o combate à doença, podemos citar que a disseminaçáo da COVID-19 no contexto de uma sociedade globalizada não possui precedentes e, com isso, demanda aprendizado ao mesmo tempo que se convive com a pandemia. Da mesma forma, a falta de conhecimento sobre a dimensão do problema originou muitos pontos de resistência ao cumprimento das recomendaçóes de prevenção e fadiga da populaçáo relativa às restriçóes, culminando em episódios de aglomeraçóes em espaços públicos, indesejável em qualquer período de uma pandemia desta dimensão.

Independentemente do resultado obtido pelas medidas adotadas, o risco de contágio e aumento do número de casos permanecem. $\mathrm{O}$ alerta permanece devido à sequência de feriados prolongados com intensa movimentaçáo do comércio, realização de eventos e festas associadas à entrada na Fase Verde do Plano São Paulo, movimentaçáo e aglomeraçáo de pessoas nas campanhas eleitorais, aumento da circulação de pessoas com o retorno às aulas, relaxamento dos cuidados.

Todos esses riscos, fizeram com que eventos tradicionais de final de ano fossem suspensos ou adiados, como a Festa de Réveillon e o Carnaval. Para isso, algumas sugestôes devem ser consideradas pelo poder público para a prevenção do inevitável aumento do contágio em nosso meio, como: 1. Monitoração regional dos indicadores; 2. Envolvimento da Vigilância Sanitária municipal e agentes de saúde do Programa de Saúde da Família para gestáo dos casos e seus contatos; 3 . Aumento da disponibilidade de testes PCR e análise de resultados por regiāo; 4. Monitoramento do número de casos alocados via CROSS; 5. Equipamento de leitos e unidades de Prontoatendimento destinados à COVID-19; 6 . Mobilização de equipes na divulgação de cuidados preventivos para a população; 7 . Contribuiçáa das atividades do comércio, do esporte e outras atividades na orientação da sociedade; 8 . Reforço à necessidade do uso de máscaras associada ao distanciamento social e evitar aglomeraçóes; 9. Alerta do risco de contágio no ambiente doméstico de familiares e idosos com comorbidades.

\section{Conclusão}

A experiência com a cidade de Ipaussu demonstrou que é possível implementar, em escala municipal, todas as recomendaçóes de prevenção orientadas pelo Plano São Paulo 
para o combate ao coronavírus. As açóes comunitárias devem ser contínuas e envolver toda a população até o advento de tratamento ou vacina. Após a flexibilização das medidas, o risco de crescimento agudo do número de casos, internaçóes e óbitos é real, sendo que as principais ferramentas para preservar o sistema de saúde de um colapso são o incremento da testagem, rastreamento e isolamento dos casos confirmados de maneira precoce. É fundamental o envolvimento dos setores públicos e administrativos nas medidas técnicas restritivas e de educação buscando o comprometimento da comunidade na adesão ao uso de máscaras faciais e distanciamento social, evitando qualquer tipo de aglomeração de risco, principalmente em festas e comemoraçóes.

\section{REFERÊNCIAS BibLIOGRÁFICAS}

1. Novel coronavirus (2019-nCoV). https: //www.who.int/emerencies/diseases/ novel-coronavirus-2019. Accessed on November 27, 2020.

2. Lewnard JA, Lo NC. Scientific and ethical basis for social-distancing interventions against COVID-19. Lancet Infect Dis. 2020;20(5):631-633. DOI:10.1016/ S1473-3099(20)30190-0.

3. Imprensa Oficial do Estado de São Paulo. Plano São Paulo. Decreto No 64.994, de 28 de maio de 2020.

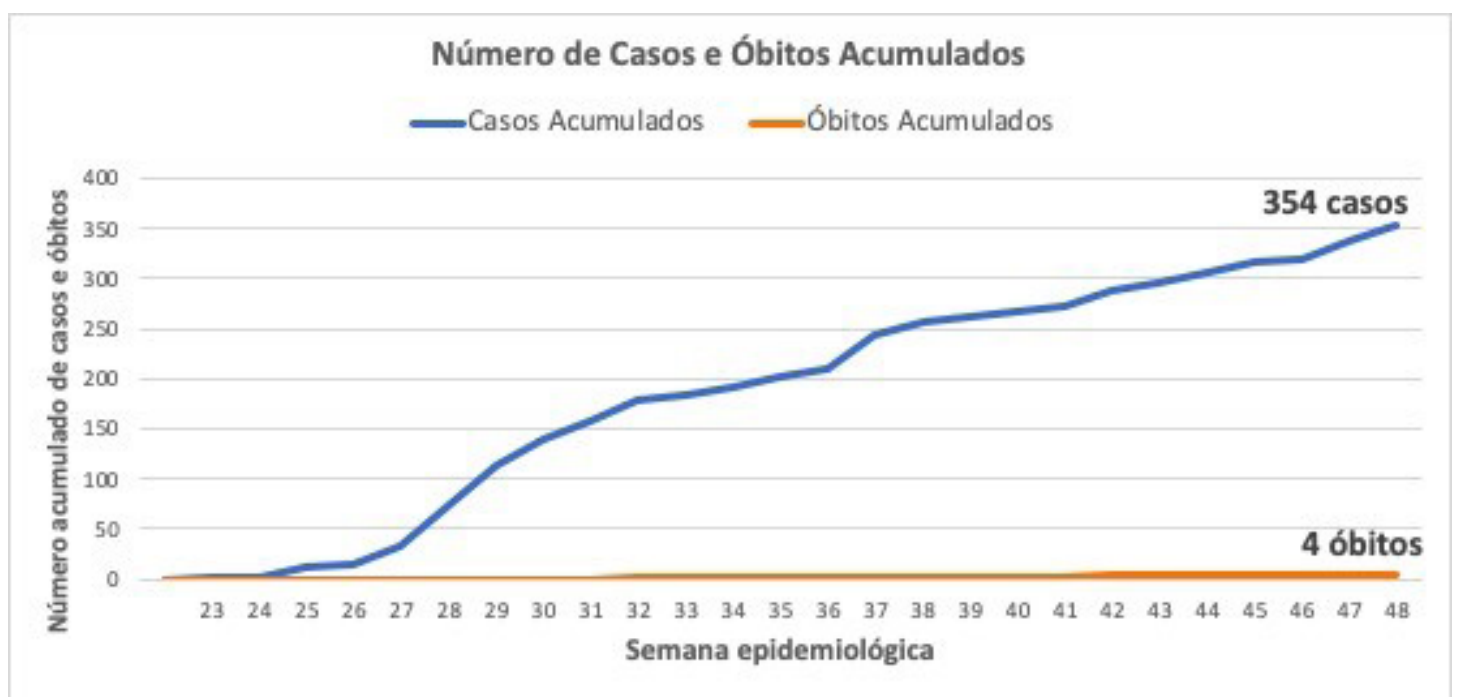

Figura 1. Número acumulado de casos de COVID-19 e óbitos na cidade de Ipaussu/SP entre Maio e Novembro/2020. 


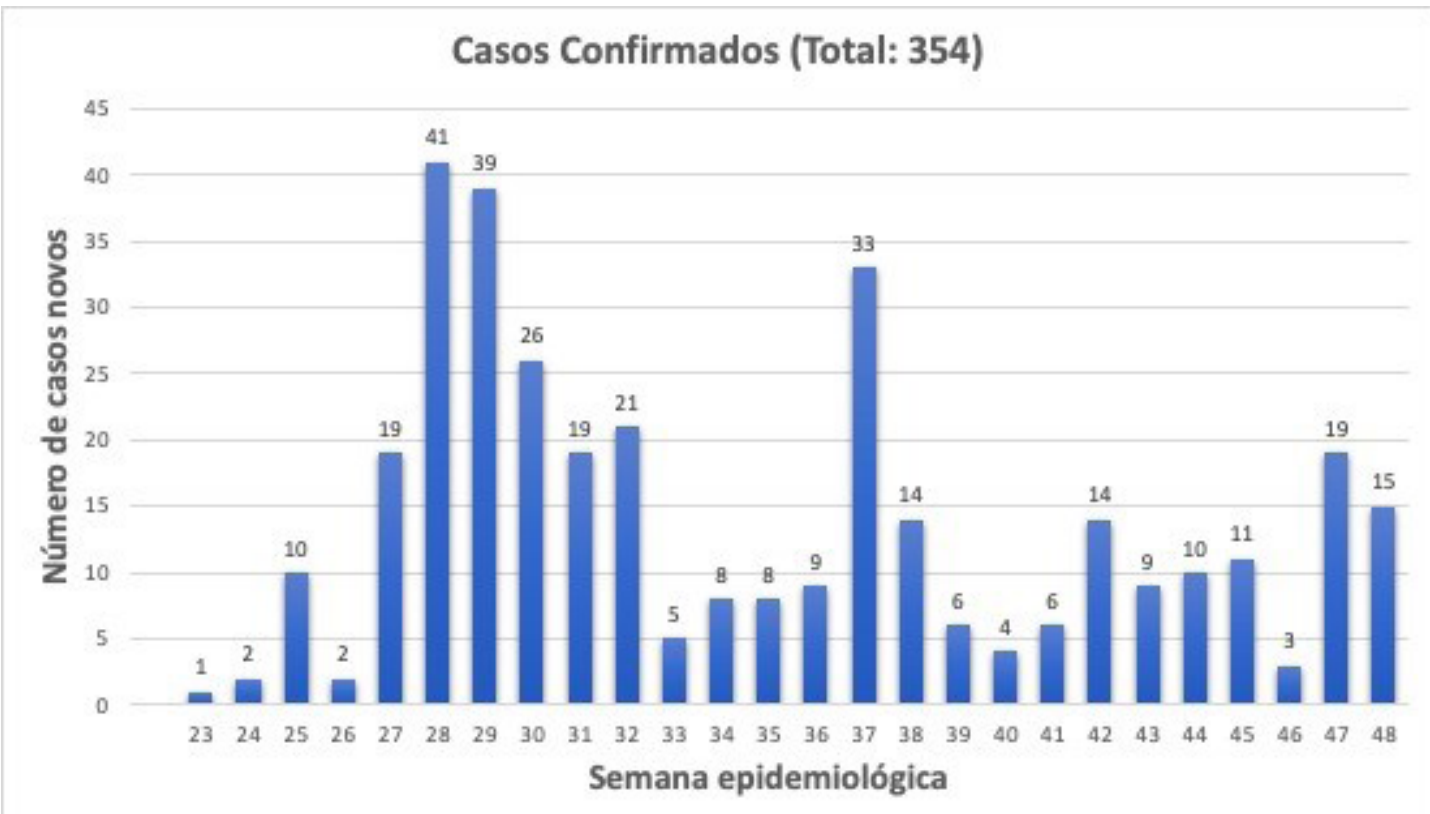

Figura 2. Número de casos de COVID-19 confirmados, por semana epidemiológica, na cidade de Ipaussu/SP, entre Maio e Novembro/2020.

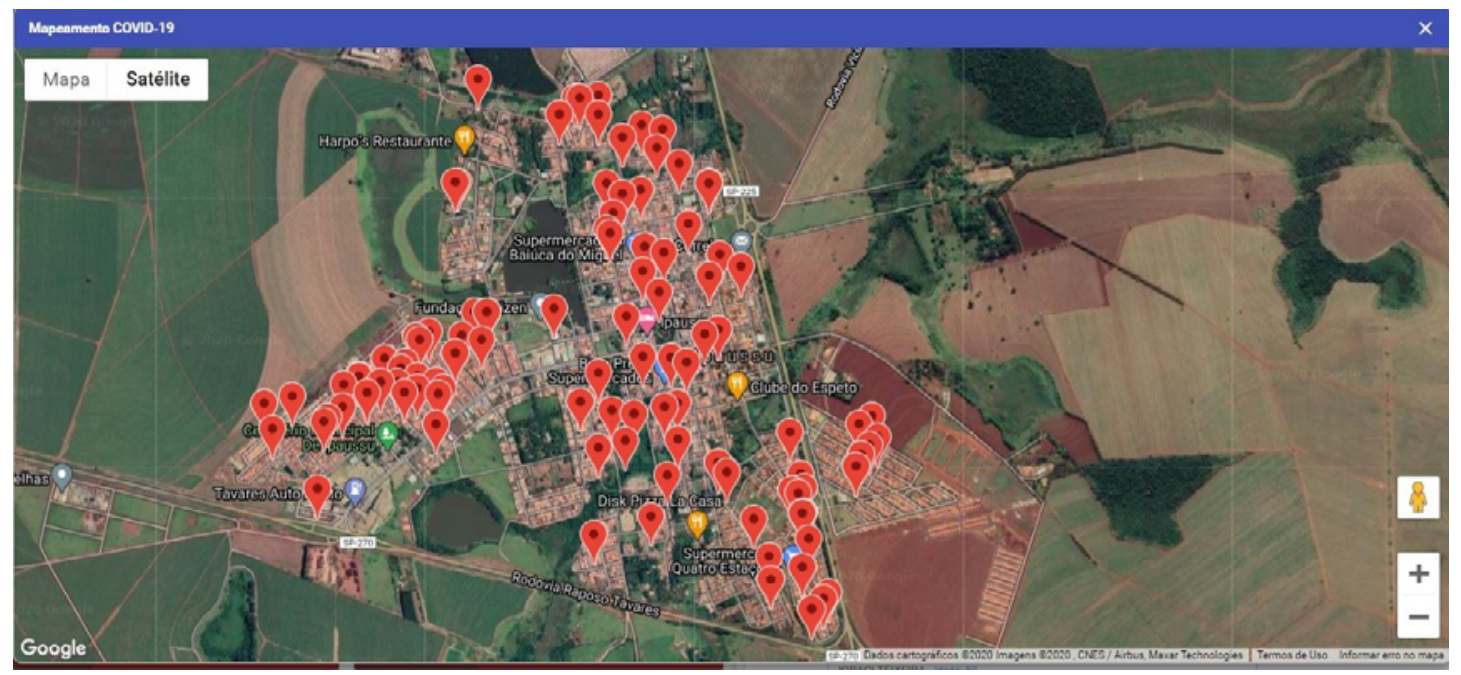

Figura 3. Distribuição geográfica dos casos de COVID-19 na região urbana de Ipaussu/SP, entre Maio e Novembro/2020. 


\begin{tabular}{|c|c|c|c|c|c|c|}
\hline $\begin{array}{l}\text { Idade } \\
\text { (anos) }\end{array}$ & $\begin{array}{c}\text { População } \\
\text { (2010) }\end{array}$ & Casos & $\begin{array}{l}\text { Incidência } \\
\text { dos casos } \\
\text { (por hab.) }\end{array}$ & Óbitos & $\begin{array}{l}\text { Incidência } \\
\text { de óbitos } \\
\text { (por hab.) e } \\
\text { letalidade }\end{array}$ & $\begin{array}{l}\text { Resultado } \\
\text { do Inquérito } \\
\text { sorológico }\end{array}$ \\
\hline$>60$ & 2.258 & $51(2,3 \%)$ & 1 em 44 & $4(0,2 \%)$ & 1 em 564 (9,8\%) & \\
\hline $40-59$ & 3.754 & $109(2,9 \%)$ & 1 em 34 & - & - & - \\
\hline $20-39$ & 4.645 & $146(3,1 \%)$ & 1 em 32 & - & - & - \\
\hline $10-19$ & 2.016 & $28(1,4 \%)$ & 1 em 72 & - & - & - \\
\hline $0-9$ & 1.833 & $20(1,1 \%)$ & 1 em 92 & - & - & - \\
\hline TOTAL & 14.506 & $354(2,4 \%)$ & 1 em 41 & $4(0,03 \%)$ & 1 em $3.626(1,3 \%)$ & $12,2 \%$ \\
\hline
\end{tabular}

Tabela 1. Distribuição dos casos confirmados por RT-PCR, óbitos e letalidade conforme faixa etária e resultado do inquérito sorológico na cidade de Ipaussu/SP. 